\title{
Pola Asuh Orang Tua untuk Meningkatkan Motivasi Belajar Anak di Desa Pecuk Mijen Demak pada Pembelajaran Daring di Masa Pandemi Covid-19
}

\author{
Indah Farah Dina Solekah', Deka Setiawan², Erik Aditia Ismaya ${ }^{3}$ \\ 1,2,3Universitas Muria Kudus, Indonesia \\ E-mail: indahfarahdinasolekah@gmail.com,deka.setiawan@umk.ac.id,erik.aditia@umk.ac.id
}

\begin{abstract}
Article Info
Article History

Received: 2021-12-27

Revised: 2022-01-22

Published: 2022-02-04

Abstract

The problem studied in this study aims to analyze the form of parenting applied by parents in motivating children to learn to be brave. This research uses a qualitative method with a case study approach. In data collection, researchers used the methods of observation, interviews, documentation, and field. The data analysis technique used is qualitative data analysis. The results of this study found that the parenting pattern of

Keywords:

Parenting;

Learning Motivation;

Online Learning. parents in Pecuk Village, Mijen District, Demak Regency, was using democratic parenting, permitive parenting, and authoritarian parenting. The effect of parenting on children's learning motivation in Pecuk Village, Mijen District, Demak Regency shows that parents providing good care in accordance with children's development can play an important role in learning motivation.
\end{abstract}

\begin{tabular}{l}
\hline Artikel Info \\
\hline Sejarah Artikel \\
Diterima: 2021-12-27 \\
Direvisi: 2022-01-22 \\
Dipublikasi: 2022-02-04
\end{tabular}

\section{Abstrak}

Persoalan yang dikaji pada penelitian ini bertujuan untuk menganalisis bentuk pola asuh yang diterapkan orang tua dalam memotivasi anak pada pembelajaran daring. Penelitian ini menggunakan metode kualitatif dengan pendekatan studi kasus. Pada pengumpulan data, peneliti menggunakan metode observasi, wawancara, dokumentasi dan catatan lapangan. Teknik analisis data yang digunakan yakni analisis data kualitatif. Hasil penelitian ini didapatkan bahwa pola asuh orang tua di Desa Pecuk Kecamatan Mijen Kabupaten Demak yaitu menggunakan pola asuh demokratis, pola

Kata kunci:

Pola Asuh Orang Tua; Motivasi Belajar;

Pembelejaran Daring. asuh permitif, dan pola asuh otoriter. Pengaruh Pola asuh terhadap motivasi belajar anak di Desa Pecuk Kecamatan Mijen Kabupaten Demak menunjukan bahwa orang tua memberikan pengasuhan yang baik sesuai dengan perkembangan anak dapat memberikan peranan penting terhadap motivasi belajar.

\section{PENDAHULUAN}

Pandemi COVID-19 membuat semua sendi kehidupan mengalami perubahan yang berarti termasuk perubahan tatanan dalam dunia pendidikan, pendidikan merupakan salah satu hal yang terpenting bagi manusia, baik pendidikan formal maupun non formal mampu membentuk kepribadian manusia lebih baik, sopan, cerdas, sukses, bertanggung jawab dan membawa arah ke negara lebih maju lagi. Oleh karena itu pentingnya pendidikan banyak orang yang pergi keluar daerah bahkan ke luar negeri demi keberhasilan pendidikan yang mereka inginkan salah satu faktor penting untuk berhasil dalam pendidikan mampu belajar adalah motivasi belajar (Arumsari ,2017). Pembelajaran yang dilasanakan pada sekolah dasar juga menggunakan pembelajaran daring/jarak jauh dengan melalui bimbingan orang tua, sebagai mana yang diungkapkan oleh Nakayama (2007) bahwa dari semua literatur dalam e-learning mengindikasikan bahwa tidak semua peserta didik akan sukses dalam pembelajaran online, hal ini dikarenakan faktor lingkungan belajar dan karakteristik peserta didik (Nakayama, 2007).
Pola asuh orang tua siswa dalam sistem belajar dirumah ini tidak bisa dipungkiri, jika sekarang ini dokter sebagai garda terdepan dalam penanganan covid-19, maka sekarang orang tualah baik itu ayah maupun ibu menjadi garda terdepan untuk mengawal anak anaknnya tetap belajar dirumah masing-masing, disinilah pola asuh orang tua sangat dibutuhkan, sejalan pendapat Mu'tadin (2002) menyatakan bahwa pola asuh merupakan interaksi antara anak dan orang tua selama mengadakan kegiatan pengasuhan yang berarti orang tua mendidik, membimbing dan mendisiplinkan serta melindungi anak sehingga memungkinkan anak untuk mencapai tugas-tugas perkembangannya. Menurut Slameto (2010:60-61) mengatakan bahwa cara orang tua mendidik anak sangat berpengaruh terhadap belajar anal, sikap dan perlakuan orang tua yang tidak memperhatikan anak seperti acuh tak acuh, tidak memperhatikan kebutuhan anak-anak dalam belajar akan mengakibatkan kegagalan dalam prestasi pendidikan anak, terkadang orang tua kurang peduli terhadap kegiatan anak sekolah tanpa mengetahui perkembangan anaknya. Hal ini dapat terjadi 
kemungkinan besar ada beberapa orang tua yang sibuk dengan bekerja sehingga orang tua mengesampingkan perhatian perkembangan pendidikan anak.

Orang tua dan anak adalah satu ikatan dalam jiwa, setiap orang tua yang memiliki anak selalu ingin memelihara, membesarkan dan mendidiknya, menurut Djamarah (2014:44) mengatakan bahwa orang tua dan anak dalam satu keluarga memiliki kedudukan yang berbeda, dalam pandangan orang tua, anak adalah buah hati dan tumpuan masa depan yang harus dibimbing dan diasuh. Membimbing dengan cara membantu, melatih dan sebagainya dan mengasuh dalam arti menjaga dengan cara merawat, dan mendidiknya agar menjadi anak yang cerdas. Nashar (2004:11) Motivasi belajar yang dimiliki siswa dalam setiap kegiatan pembelajaran sangat berperan untuk meningkatkan prestasi belajar siswa dalam mata pelajaran tertentu, sedangkan Sari (2021) motivasi belajar yaitu tindakan dari diri siswa maupun orang lain yang mempengaruhi ataupun mendorong seseorang agar melakukan aktivitas belajar.

Berdasarkan pada hasil observasi yang dilaksanakan disekitar lingkungan tepatnya desa Pecuk RT.03 RW.03 dengan mentaati protokol kesehatan karena adanya wabah Covid-19 dapat diperoleh informasi sebagai berikut yaitu menunjukan bahwa masih banyak orang tua yang belum sadar akan perannya dalam memberikan motivasi kepada anaknya, hal ini terlihat pada saat siswa mendapatkan tugas dari guru dan harus dikerjakan dirumah karena pembelajaran pada saat ini harus dilakukan dirumah masing-masing siswa dengan bimbingan orang tua sendiri siswa kurang memberikan minatnya dalam pembelajran mengerjakan tugas. Terdapat orang tua dan anak yang kurang paham dengan perintah tentang pengerjaan tugasnya, hal ini akan membuat orang tua menjadi kebingungan untuk membimbing anak mengerjakan tugas karena belum terlalu paham dengan tugas yang diberikan guru, dengan waktu dirumah yang cukup lama anak banyak memiliki waktu yang cukup lama untuk mengerjakan tugas, tetapi ada juga anak yang lebih memilih untuk pergi bermain keluar rumah untuk bermain, berkumpul teman sebayanya dilingkungan sekitarnya untuk bermain game, sehingga lupa dengan tugasnya sendiri, sementara itu orang tua sibuk dengan pekerjaannya masing-masing dan tidak mengetahui jika anaknya mendapatkan tugas belajar dirumah yang diberikan guru.

\section{METODE PENELITIAN}

Penelitian ini dilaksanakan di Desa Pecuk Kecamatan Mijen Kabupaten Demak, penelitian ini menggunakan metode kualitatif dengan pendekatan studi kasus. Moleong (2007:6) menyatakan bahwa metode penelitian kualitatif adalah penelitian yang bermaksud untuk memahami fenomena tentang apa yang dialami oleh subjek penelitian misalnya perilaku, persepsi, motivasi, tindakan dengan disajikan secara holistik dan dengan cara deskripsi dalam bentuk kata-kata dan bahasa, pada suatu konteks khusus yang alamiah dengan memanfaatkan berbagai metode alamiah. Data primer dalam penelitian ini yaitu sebanyak 5 orang tua anak, 5 anak sekolah dasar Desa Pecuk RT 03 dan RW 03 Kecamatan Mijen Kabupaten Demak, serta guru sekolah dasar Pada pengumpulan data, peneliti menggunakan metode observasi, wawancara, dokumentasi, dan catatan lapangan. Teknik analisis data yang digunakan meliputi reduksi data, penyajian data dan verifikasi data.

\section{HASIL DAN PEMBAHASAN}

Pendidikan yang ideal yang akan didapat oleh seorang anak adalah pendidikan yang mampu memberikan dampak yang positif bagi seorang anak itu sendiri, hal tersebut tidak akan pernah dari peran orang tua, karena orang tua merupakan pendidikan pertama bagi anaknya sehingga sangat mempengaruhi motivasi belajar pada anak. Silahudin (2017:20) menjelaskan bahwa karakter seorang individu terbentuk sejak dia kecil karena pengaruh genetik dan lingkungan sekitar. Proses pembentukan karakter, baik disadari maupun tidak akan mempengaruhi cara individu tersebut memandang diri dan lingkungannya akan tercemin dalam perilakunya sehari-hari. Seiring dengan perkembangan zaman yang disertai dengan berkembangnya teknologi informasi telah mengakibatkan pergeseran nilai dan banyak perilaku menyimpang yang terjadi pada anak-anak, sehingga orang tua dan lembaga pendidikan serta lingkungan masyarakat perlu memberikan perhatian serius dalam membangun karakter anak tersebut.

Fitriani (2015: 102) menyebutkan bahwa ada tiga macam pola asuh yaitu pola asuh otoriter, pola asuh demokratis, dan pola asuh permitif. Pola asuh otoriter adalah pola asuh ydengan aturan yang diterapkan sepihak oleh orang tua tanpa memandang dan memperlihatkan perasaan dan keadaan si anak. Pola asuh demokratis adalah pola asuh yang memberikan kebebasan 
bagi anak dalam menentukan pilihan sebagai bentuk aktualisasi diri serta orang tua tetap memberikan arahan dan bimbingan terhadap anak. Dan pola asuh permitif adalah pola asuh yang mengedepankan kebebasan bagi anak dalam memperilaku tanpa adanya batasan sesuai kemauannya sendiri, dalam penelitian yang dilakukan oleh peneliti di Desa Pecuk RT 03 RW03 Kecamatan Mijen Kabupaten Demak pola asuh yang diberikan oleh orang tua akan mempengaruhi terhadap motivasi belajar anak. Dengan pola asuh diterapkan berbeda-beda pada masing-masing orang tua maka dampak yang didapatkan pada anak juga berbeda. Bentuk pola asuh orang tua siswa dapat dilihat dalam tabel dibawah ini.

Tabel 1. Bentuk Pola Asuh Orang Tua Siswa

\begin{tabular}{|c|c|c|c|c|c|}
\hline $\begin{array}{l}\mathbf{N} \\
\mathbf{o}\end{array}$ & $\begin{array}{c}\text { Nama } \\
\text { Orang } \\
\text { Tua }\end{array}$ & $\begin{array}{l}\text { Nama } \\
\text { Anak }\end{array}$ & $\begin{array}{l}\text { Pekerja- } \\
\text { an }\end{array}$ & $\begin{array}{c}\text { Tingkat } \\
\text { Perekono } \\
\text { mian }\end{array}$ & $\begin{array}{c}\text { Pola } \\
\text { Pengasu- } \\
\text { han }\end{array}$ \\
\hline 1. & L & MHM & Penj & $\begin{array}{l}\text { Menengah } \\
\text { kebawah }\end{array}$ & $\begin{array}{c}\text { Demokra- } \\
\text { tis }\end{array}$ \\
\hline 2. & NS & NAZ & $\begin{array}{c}\text { Ibu rumah } \\
\text { tangga }\end{array}$ & $\begin{array}{l}\text { Menengah } \\
\text { keatas }\end{array}$ & Permitif \\
\hline 3. & $\mathrm{EH}$ & MAR & $\begin{array}{l}\text { Pedagang } \\
\text { makanan }\end{array}$ & Menengah & Otoriter \\
\hline 4. & MW & DAS & wira & $\begin{array}{l}\text { Menengah } \\
\text { keatas }\end{array}$ & $\begin{array}{c}\text { Demokra- } \\
\text { tis }\end{array}$ \\
\hline 5. & $S$ & AS & $\begin{array}{c}\text { Karyawan } \\
\text { swasta }\end{array}$ & Menengah & $\begin{array}{c}\text { Demokra- } \\
\text { tis }\end{array}$ \\
\hline
\end{tabular}

Berdasarkan tabel di atas dapat diketahui bahwa bentuk pola asuh yang terapkan orang tua di Desa Pecuk Kecamatan Mijen Kabupaten Demak menerapkan pola pengasuhan demokratis mulai dari anak kecil hingga anak sudah terbiasa yang diterapkan orang tuanya. Tiga dari lima orang tua menerapkan pola asuh demokratis terhadap anak yang bertujuan untuk memberikan kebebasan pada anak, akan tetapi orang tua tetap melakukan bimbingan terhadap anak. Pratiwi (2020: 25) mengatakan bahwa pola asuh demokratis adalah orang tua yang memiliki karakteristik pengasuhan pada anak dengan memberikan keleluasaan pada anak untuk berkembang namun terdapat aturan yang tidak boleh di langgar oleh anak, orang tua demokratis cenderung memiliki ciri-ciri mampu megikuti dunia anak dan dapat bekerjasama dengan anak, serta satu dari lima orang tua menerapkan pola pengasuhan otoriter pada anak yaitu dengan memberikan hukuman fisik terhadap anaknya serta menuntut anak untuk harus ikut kemauan dari orang tuanya, jika hal tersebut terus dibiarkan lama kelamaan akan menjadi mengganggu mental dan juga perkembangan anak dimasa yang akan datang. Joni (2015: 44) memaparkan bahwa pola asuh otoriter adalah pola pengasuhan anak yang bersifat memaksa, keras dan kaku dimana orang tua membuat aturan yang harus dipatuhi anak tanpa memperhatikan perasaan anak, orang tua akan marah dan emosi jika anak tidak melakukan apa yang diperintahkan, dari tingkat perekonomian informan dari lima informan juga beragam ada keluarga yang memiliki tingkat perekonomian me-nengah kebawah, menengah, dan menengah keatas, serta pekerjaan orang tua juga Sangat memperngaruhi bagaimana orang tua dalam memberikan pengasuhan terhadap anaknya. Karena peran orang tua dalam memberikan motivasi belajar juga berdampak pada psikologis siswa, jika psikologis anak baik, jiwa dan perasaan anak akan bahagia maka anak akan melakukan sesuatu dengan maksimal, hal tersebut juga menutup kemungkinan anak akan belajar secara maksimal dengan dorongan motivasi yang orang tua berikan.

Hasil penelitian yang dilakukan oleh Afiif dan Makkulau (2016) menyatakan bahwa motivasi belajar peserta didik dipengaruhi oleh beberapa faktor diantaranya adalah pola asuh orang tua. Rostiana (2015) juga menyatakan bahwa semakin baik pola asuh orang tua, maka semakin tinggi motivasi anak untuk belajar. Dampak positif dari pola asuh orang tua yang baik diantaranya anak akan kreatif, bertanggung jawab, dan disiplin sehingga dapat meningkatkan hasil belajar. Motivasi belajar anak di Desa Pecuk dapat dilihat dalam tabel 2 .

Tabel 2. Motivasi Belajar Anak

\begin{tabular}{ccccc} 
NO & Nama & Kelas & $\begin{array}{c}\text { Pola } \\
\text { Pengasuhan }\end{array}$ & $\begin{array}{c}\text { Motivasi } \\
\text { Belajar }\end{array}$ \\
\hline 1. & MHM & IV & Demokratis & Tinggi \\
2. & NAZ & VI & Permitif & Sedang \\
3. & MAR & VI & Otoriter & Rendah \\
4. & DAS & V & Demokratis & Tinggi \\
5. & AS & V & Demokratis & Tinggi \\
\hline
\end{tabular}

Sikap dan peran orang tua yang selalu memberikan perhatikan anak akan mem-berikan dorongan anak untuk selalu semangat dalam belajar, pola asuh yang diberikan orang tua juga mampu berdampak positif kepada anak khusunya pada anak di Desa Pecuk Kecamatan Mijen Kabupaten Demak. Peran orang tua sangat mempengaruhi motivasi belajar anak seperti yang disebutkan Hasan (2010) peran orang tua sangat penting dalam proses pendidikan anak. Peran keluarga dapat berupa pola asuh yang diterapkan oleh kedua orang tua. perbedaan pola asuh nantinya akan menghasilkan kepribadian yang berbeda pula. Berkaitan dengan hal tersebut maka peran pola asuh yang demokratis 
akan mampu memberikan peranan yang postitif bagi anak di Desa Pecuk Kecamatan Mijen Kabupaten Demak.

\section{SIMPULAN DAN SARAN}

\section{A. Simpulan}

Berdasarkan hasil penelitian mengenai pola asuh orang tua terhadap motivasi belajar anak sekolah dasar yang dilakukan di Desa Pecuk Kecamatan Mijen Kabupaten Demak, maka kesimpulan yang dapat diambil oleh peneliti sebagai berikut:

1. Pola asuh orang tua di Desa Pecuk Kecamatan Mijen Kabupaten Demak yang telah dipilih berdasarkan latar belakang pendidikan, kondisi ekonomi dan juga pekerjaan orang tua cukup beragam yaitu menggunakan pola asuh demokratis, pola asuh permitif, dan pola asuh otoriter, akan tetapi berdasarkan hasil dari penelitian kebanyakan menggunakan pola asuh demokratis yaitu tiga dari lima anak menggunakan pola asuh demokratis, satu dari lima anak menggunakan pola asuh permitif dan satu dari lima anak menggunakan pola asuh otoriter. Pola asuh demokratis memiliki ciri lebih memberikan kebebasan kepada anak dalam menentukan pilihan dan melakukan sesuatu akan tetapi orang tua tetap mengontrol, memperhatikan serta tetap memberikan bimbingan dan arahan, kemudian pola asuh permitif menunjukan orang tua lebih membebaskan anak melakukan apa saja dalam arti memberikan kebebasan pada anak tanpa adanya batasan. Dan pola asuh otoriter menunjukan orang tua sering memberikan hukuman fisik ketika tidak mengikuti aturan.

2. Pengaruh Pola asuh terhadap motivasi belajar anak di Desa Pecuk Kecamatan Mijen Kabupaten Demak menunjukan bahwa orang tua memberikan pengasuhan yang baik sesuai dengan perkembangan anak dapat memberikan peranan penting terhadap motivasi belajar, anak yang memiliki tingkat motivasi belajarnya tinggi cenderung pada orang tua yang pola pengasuhan meggunakan pola asuh demokratis, anak yang memiliki tingakt motivasi belajarnya rendah cenderung pada orang tua yang pola pengasuhannya otoriter, sedangkan anak yang memiliki tingkat motivasi belajarnya sedang cenderung pada pola pengasuhan permitif.

\section{B. Saran}

Adapun saran yang dapat disampaikan berdasarkan hasil penelitian ini yakni untuk orang tua dan guru dapat berkolaborasi mendidik anak guna memaksimalkan belajarnya dimasa pandemi covid-19, kemudian saran untuk peneliti selanjutnya diharapkan dapat merujuk serta mengembangkan penelitian ini.

\section{DAFTAR RUJUKAN}

Afiif, A., \& Makkulau, A. F. B. (2016). Motivasi belajar biologi siswa sma ditinjau dari pola asuh orangtua dan dukungan sosial teman sebaya. Jurnal Psikologi Perseptual, 1(2), 62-69.

Aiayatinnaba Nur, Anwar Sutoyo. 2016. Peran Orang Tua Dalam Memotivasi Siswa. Indonesian Journal of Guidance and Counseling. 5 (4). 52-57.

Arumsari, C. (2017). Strategi konseling latihan asertif untuk mereduksi perilaku bullying. Journal of Innovative Counseling: Theory, Practice, and Research, 1(01), 3139.

Djamarah, \& Syaiuful Bahri. (2017). Pola Asuh Orang Tua dan Komunikasi dalam Keluarga : Upaya Membangun Citra Membentuk Pribadi Anak. Jakarta: Rineka Cipta.

Fitriani, L. (2015). Peran Pola Asuh Orang Tua dalam Mengembangkan Kecerdasan Emosi Anak. Lentera, 17(1), 93-110.

Hamalik, \& Oemar. (2007). Psikologi Belajar dan Mengajar. Bandung: Sinar Baru Algesido.

Hasan, M. (2010). PAUD (Pendidikan Anak Usia Dini). Jogjakarta: DIVA Press.

Joni, J. (2015). Hubungan Pola Asuh Orang Tua terhadap Perkembangan Bahasa Anak Prasekolah (3-5 Tahun) Di PAUD AlHasanah Tahun 2014. Jurnal Obsesi: Jurnal Pendidikan Anak Usia Dini, 1(1), 42-48.

Mawarsih, S. E., \& Hamidi, N. (2013). Pengaruh perhatian orang tua dan motivasi belajar terhadap prestasi belajar siswa sma negeri jumapolo. Jupe-Jurnal Pendidikan Ekonomi, 1(3). 
Moleong Lexy J. (2014). Metodologi Penelitian Kualitatif. Bandung: Rosda.

Mu'tadin, Z. (2002). Mengenal Cara Belajar Individu. E-psikologi. com.

Nakayama, M., Yamamoto, H., \& Santiago, R. (2007). The Impact of Learner Characteristics on Learning Performance in Hybrid Courses among Japanese Students. Electronic Journal of ELearning, 5(3), 195-206.

Nashar. (2004). Peranan Motivasi dan Kemampuan Awal dalam Kegiatan Pembelajaran. Jakarta: Delia Press.

Pratiwi, R. H. I. A. (2020). POSISI ORANG TUA DEMOKRATIS DALAM PEMBENTUKAN DISIPLIN BELAJAR SISWA SEKOLAH DASAR. Pendidikan Bela Negara, 24, 28.

Rostiana, I., Wilodat, W., \& Alya, M. N. (2015). Hubungan Pola Asuh Orang Tua Dengan Motivasi Anak Untuk Bersekolah Di Kelurahan Sukagalih Kecamatan Sukajadi Kota Bandung. SOSIETAS, 5(2).
Sadirman, A. (2011). Interaksi dan Motivasi Belajar Mengajar. Jakarta: Raja Grafindo.

Sari, W. N., Murtono, M., \& Ismaya, E. A. (2021). PERAN GURU DALAM MENINGKATKAN MOTIVASI DAN MINAT BELAJAR SISWA KELAS V SDN TAMBAHMULYO 1. Jurnal Inovasi Penelitian, 1(11), 2255-2262.

Silahuddin, S. (2017). Urgensi Membangun Karakter Anak Sejak Usia Dini. Bunayya: Jurnal Pendidikan Anak, 3(2), 18-41.

Slameto. 2010. Belajar \& Faktor-Faktor Yang Mempengeruhinya. Jakarta: Rineka Cipta. Jurnal Kreatif Februari 2017.

Wibowo, Agus, \& Gunawan. (2015). Pendidikan Karater Berbasis Kearifan Lokal. Yogyakarta: Pustaka Belajar. 